\title{
El fascismo: \\ la barbarie moderna (I)
}

José Ramón CataLÁN

Departamento de Filosofía

UCA, San Salvador

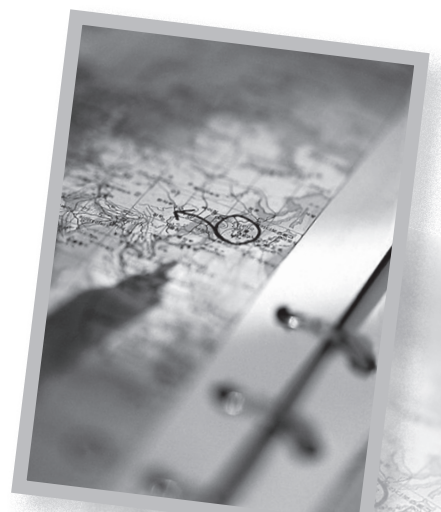

RESUMEN: El presente ensayo aporta una reflexión sobre el fascismo. El autor es consciente de lo que advierten las víctimas del mismo: el fascismo no debe comprenderse. ¿Qué sentido tiene reflexionar acerca de algo que no se "debe comprender"? En esta primera parte del ensayo se dilucida esta cuestión. Acto seguido, se presentan las visiones del fascismo de Lévinas y Benjamin. Finalmente, y para concluir esta primera entrega, el autor muestra el llamado influjo "espiritual" del nazismo y cómo se creó el mito.

ABSTRACT: This essay provides a reflection on Fascism. The author is aware of what its victims warn: Fascism must not be understood. Does it have any sense to reflect on something that "must not be understood"? In this first part of the essay, the question is elucidated. Next, the visions on Fascism by Lévinas and Benjamin are presented. Finally, and concluding with this first part, the author shows the so-called "spiritual" influx of Fascism and how its myth was created. 


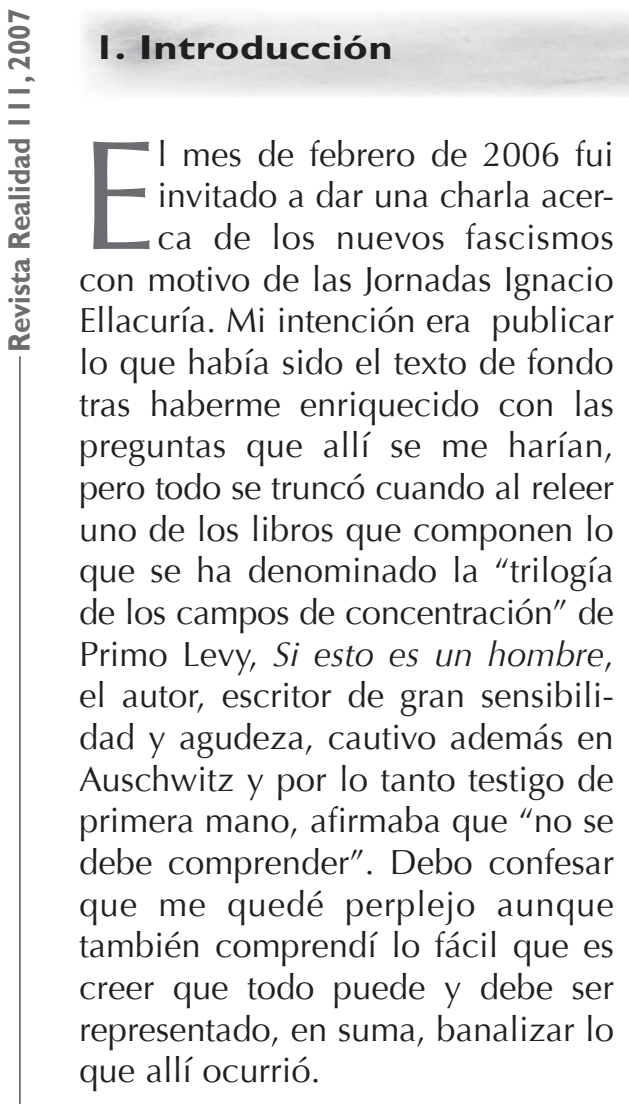

En cualquier caso, me hizo reflexionar: es una víctima quien lo demanda, $y$ en eso estaba cuando pude hacerme con un material inestimable por su profundidad y calidad. La lectura de las Tesis de la historia y Para una crítica de la violencia de Walter Benjamin, así como parte de la obra que Reyes Mate dedica al asunto judío, Memorias de Auschwitz, o Medianoche en la historia, o La estrella de la redención de Franz Rosenzweig, me dio argumentos, no sólo para "dialogar" con Primo Levy, sino que me permitió adoptar otro punto de vista a la hora de enfocar un asunto tan vidrioso como el nazismo. ¿Qué sentido tiene escribir acerca de algo que no se "debe comprender"? ¿No es justamente comprender lo que queremos? Considero tan importante este punto que a él le dedico el segundo epígrafe. Los epígrafes tercero y cuarto se ocupan de las respectivas visiones del fascismo presentaron E. Levinas y W. Benjamin. Hay muchas pero la de estos dos "avisadores del fuego"1 son quizá las más originales. Levinas nos permitirá ver las bases biológicas en las que echa raíz el racismo. Benjamin por su parte, nos introducirá en el mundo del estado de excepción y demostrará lo moderno que es el fascismo y lo mal que se asombraron sus contemporáneos. En el quinto epígrafe intentaré mostrar el influjo "espiritual" del nazismo y cómo se creó el mito. En el sexto nos adentraremos en el Estado totalitario como la institución por excelencia en la que se apoyaron estos movimientos "revolucionarios". El séptimo lo dedico a dos grandes instituciones que marcaron definitivamente a esos movimientos: el líder carismático y la dictadura. $\mathrm{Ni}$ la propaganda ni la estética podían faltar - Benjamin decía que el nazismo era "la estetización de la "política" - y ambas aparecen en los epígrafes octavo y noveno. En el décimo hablaremos de la actualidad para reflexionar un poco sobre ella. 


\begin{abstract}
Q uizás no se puede comprender todo lo que sucedió, o no se deba comprender, porque comprender es casi justificar. Me explico: "comprender" una proposición o un comportamiento humano significa (incluso etimológicamente) contenerlo, contener al autor, ponerse en su lugar, identificarse con él. Pero ningún hombre normal podrá jamás identificarse con Hitler, Himmler, Goebbels, Eichmann e infinitos otros. Esto nos desorienta y la vez nos consuela: porque quizás sea deseable que sus palabras (y también, por desgracia, sus obras) no lleguen nunca a resultarnos comprensibles. Son palabras y actos no humanos, o peor, contrahumanos, sin precedentes históricos, difícilmente comparables con los hechos más crueles de la lucha biológica por la existencia. A esta lucha podemos asimilar la guerra: pero Auschwitz nada tiene que ver con la guerra, no es un episodio, no es una forma extremada. La guerra es un hecho terrible desde siempre: podemos execrarlo pero está en nosotros, tiene su "racionalidad, lo "comprendemos". (...) Si comprender es imposible, conocer es necesario, porque lo sucedido puede volver a suceder, las conciencias pueden ser seducidas y obnubiladas de nuevo: las nuestras también ${ }^{2}$.
\end{abstract}

¿Cómo calificar este desgarrador fragmento de Primo Levy? A mi entender es paralizante. Paralizante porque en él confluyen tanto la claridad como la oscuridad. Veámoslo.

Resulta claro porque Levy no quiere de ningún modo que este acontecimiento entre a formar parte de la razón hegeliana: "lo real es racional y lo racional es real", que sea arrastrado por el "huracán del progreso" (Benjamin), quiere que sea algo que por no ser engullido por dicha razón se convierta en algo único, algo que dé que pensar a todas las generaciones futuras. En resumidas cuentas, Auschwitz no puede ser conceptualizado, va más allá del concepto (Adorno).
Además comprender no es justificar como afirma Levy. "Comprender" es comprender, no valorar. ¿Cómo podríamos evitar la repetición de este acontecimiento si no lo comprendemos? Levy nos dice que "si comprender es imposible, conocer es necesario", y esto es lo que resulta oscuro, porque ¿qué es entonces conocer? ¿Quizá describir? Pero en este caso caeríamos en la trampa del historicismo de Ranke: "Narrar los acontecimientos tal y como ocurrieron", y ino es precisamente esta forma de escribir la historia la que una y otra vez denuncia Walter Benjamin en sus tesis? 
Articular históricamente el pasado no significa conocerlo "tal como fue en concreto", sino más bien adueñarse de un recuerdo semejante al que brilla en un instante de peligro. Corresponde al materialismo histórico retener con firmeza una imagen del pasado tal como ésta se impone, de improviso, al sujeto histórico en el momento del peligro. El peligro amenaza tanto la existencia de la tradición como a quienes la reciben. Para una y para otros consiste en entregarlos como instrumentos a la clase dominante. En cada época es preciso intentar arrancar nuevamente la tradición al conformismo que quiere apoderarse de ella. El Mesías no viene sólo como redentor, viene también como vencedor del Anticristo. El don de atizar para el pasado la chispa de la esperanza sólo toca en suerte al historiógrafo perfectamente convencido de que si el enemigo triunfa, ni siquiera los muertos están seguros. $Y$ ese enemigo no ha cesado de triunfar ${ }^{3}$.

El historiador materialista - entendiendo por materialismo, no el dogmático de la II o III Internacional, sino el que Benjamin propone en la primera de sus tesis, el que va acompañado de la teología- escoge el momento de peligro porque es hay donde surge una auténtica imagen del pasado. ¿Por qué? Porque en ese momento "se disuelve la visión confortable y perezosa de la historia como progreso ininterrumpido" ${ }^{4}$. La tarea del historiador es mostrarnos el potencial utópico de un pasado que ilumine fugazmente el presente y nos permita despertar. Pero ¿no es esto acaso comprender? $\mathrm{Y}$, por otra parte, ¿no es la tradición, aquello que se nos entrega, lo que hay que comprender?

A la primera pregunta se contestaría con un sí; a la segunda, con un no. $Y$ esto porque la tradición que conocemos es la del vencedor, la "agradable" historia del "progreso" humano capaz de acallar todas las voces de los vencidos en medio de las desgracias y catástrofes. Como muy bien precisa José Manuel Romero:

Por ello, para Benjamin, es esencial hacer saltar el "continuum" histórico existente y el continuum histórico de la transmisión cultural dominante. En la más extrema discontinuidad de los horizontes históricos, las esperanzas del colectivo oprimido del pasado sólo pueden ser objeto de rememoración y redención, no a través de la comprensión o fusión de horizontes sino mediante la praxis política emancipadora que haga saltar el continuum catastrófico de la historia. (...) Más allá de la visión idealizada de la continuidad de la tradición, (Benjamin) reconoce la discontinuidad real de la transmisión de todo lo que ha sido excluido o fagocitado por la tradición dominante ${ }^{5}$. 
Si ahora volvemos a Levy, creo que ya podemos ver con más claridad que su temor de que Auschwitz sea "comprendido" sólo es inteligible desde una hermenéutica no dialéctica, es decir, desde una hermenéutica que propone una torpe fusión de horizontes que haría asimilable un acontecimiento de esa magnitud. En resumen desde una hermenéutica lineal, la del vencedor, que presentaría ese acontecimiento como uno más - eso sí, terrible- de la historia.

Vayamos ahora a otro de los puntos en discusión. "Pero ningún hombre normal podrá jamás identificarse con Hitler, Himmler, Goebbels, Eichmann e infinitos otros", escribe Levy. ¿Qué significa normal? ¿Qué significa identificarse? $\mathrm{Si}$ "normal" es lo que se opone a lo monstruoso, Levy se equivoca porque justamente Eichmann reunía los dos calificativos, esto es justamente lo que destacó Hannah Arendt en aquel libro tan mal comprendido: Eichmann en Jerusalén. La banalidad del mal. Lo que la autora quiso destacar tras asistir en Jerusalén al juicio del citado nazi no es que el mal fuera banal, esto es, trivial, común, insustancial, sino que el mal puede anidar y tomar la forma más espantosa en tipos tan banales, esto es, triviales, comunes e insustanciales como Eichmann.

¿Qué es "identificarse"? El dramaturgo Terencio escribía en una de sus comedias: "Soy un hombre y nada humano me es ajeno". "Identificar$\mathrm{se}^{\prime \prime}$ no puede significar "aprobar" o "justificar". Creo que ocurre justo lo contrario de lo que afirma Levy, todos nos identificamos con los asesinos nazis, y precisamente por ello los reconocemos como pertenecientes al género humano y de ahí justamente brota todo nuestro horror. El espanto surge porque fueron seres humanos, hombres como nosotros, los que llevaron hasta extremos insospechados el horror; si hubiesen sido extraterrestres los autores, tendríamos más tranquila la conciencia.

"Paralizante", así calificaba el párrafo de Levy. He intentado demostrar en estas líneas que Auschwitz debe ser comprendido precisamente para que no se repita - no estoy pensando sólo en los vivos, mientras los muertos no reciban la justicia que merecen, puede repetirse-, pero no puede ser comprendido desde la verbalidad sino desde el silencio, quizá la más elocuente de la voces, desde la discontinuidad. Leamos estas líneas de E. Wiesel que al igual que Primo Levy padeció la vesania de los campos nazis:

Lo que yo intento es introducir tanto silencio como sea posible. Desearía que mi obra no sea juzgada por las palabras que he escrito, sino por su peso en silencio. Si pudiera comunicar el silencio, la incomunicabilidad, entonces habría justificado una pequeña parte de mi obra6 . 
Y ahora, éstas otras de André Neher, de gran profundidad y sen- sibilidad. La cita es larga pero estas sabias palabras lo merecen:

¿Está ya madura la filosofía para una evaluación del acontecimiento de Auschwitz entre las categorías universales del sufrimiento? De juzgar según las reacciones intelectuales suscitadas desde hace casi veinte años, cabe dudarlo, hasta tal punto aquéllas han seguido siendo superficiales, discretas y a menudo atolondradas. La mayor parte de los análisis actuales del sufrimiento olvidan la referencia a Auschwitz; algunos prefieren sustituir el sufrimiento de Auschwitz por el de Hiroshima, incluso por el de Dresde; son escasas las meditaciones que intentan interrogar a Auschwitz completamente de frente. Ahora bien, Auschwitz es, ante todo, silencio. (...) Los mártires de Auschwitz son los mártires del silencio. (... ) Silencio en primer lugar, de la ciudad concentracionaria, replegada sobre sí misma, sobre sus víctimas y verdugos, separados del mundo exterior por círculos concéntricos de Noche y Niebla. (...) Ni la comparación ni el paralelo se sostienen, nada permite asociar Auschwitz a cualquier otra cosa, porque allá - en Hiroshima, Dresde, o Coventry - los hechos fueron sonoros y el estrépito del dolor inmediatamente alcanzó y sobrecogió al mundo entero; los comunicados de guerra los glorificaron o denostaron; había testigos libres sobre el terreno; al instante al menos, acudieron socorros, eficaces o inútiles, qué más da, mientras que en Auschwitz todo se desarrolló, ejecutó, consumó, durante semanas, meses, años, en el silencio absoluto, aparte y a la deriva de la historia ${ }^{7}$.

\section{Emmanuel Lévinas: nazismo como biologismo}

— 1934, prácticamente al día siguiente de la llegada al poder de Hitler, Emmanuel Lévinas publica un artículo tan corto como denso y enjundioso en Esprit, revista católica de corte progresista y que lleva por título, "Unas reflexiones acerca de la filosofía del hitlerismo" ${ }^{\prime 8}$. En él, Levinas manifiesta que el hitlerismo es un atentado contra las cuatro columnas que sostienen la cultura occidental: el judaísmo, el cristianismo, el liberalismo y el marxismo. Afirma que la filosofía de Hitler es primaria: "el hitlerismo es el sueño de los sentimientos elementales", pero a pesar de ello, "se convierte en algo filosóficamente interesante". A continuación describe lo que cada pilar ha aportado a la cultura occidental. 
"El tiempo, condición de la existencia humana, es sobre todo condición de lo irreparable", es decir que la inmovilidad del pasado imborrable, nos condena a continuar prohibiéndonos cualquier iniciativa. Ante esta situación el judaísmo nos proporciona la solución, pues del remordimiento brota el perdón que nos alivia y por ello volvemos a empezar. En el cristianismo, la cruz nos libera y por la eucaristía que vence el tiempo, esta liberación se da cada día.

El liberalismo por su parte, "conserva un elemento fundamental bajo la forma de una razón soberana", "todo el pensamiento filosófico de los tiempos modernos tiende a colocar el espíritu humano en un plano superior al real, cava un abismo entre el hombre y el mundo". El hombre del liberalismo no elige su destino bajo el peso de una Historia, "no conoce sus posibilidades como poderes inquietos que bullen en él y lo orientan ya por una vía determinada.

La intuición fundamental del marxismo es que el espíritu humano no aparece como pura libertad, "el espíritu es presa de necesidades materiales", pero este encadenamiento no tiene nada de radical, "la conciencia individual determinada por el ser, no es tan impotente como para no conservar - en principio al menos - el poder de romper el encantamiento social que aparece desde entonces como extraño a su esencia. Tomar conciencia de la situación social es para el propio Marx liberarse del fatalismo que ésta comporta."

Tras este breve repaso en el que predomina un apetito de transcencencia o cuando menos de liberación, Lévinas analiza la relación cuerpo-espíritu y se remonta a Descartes. Según Lévinas, nunca imaginó Descartes el daño que causaría la división que propuso entre la sustancia pensante y la extensa, relegando a ésta última a un estado de pura naturaleza. $Y$ es que para nuestro "avisador del fuego", hay una identidad entre el yo y el cuerpo que impide cualquier dualidad.

El cuerpo no es simplemente un accidente feliz o desdichado que nos pone en contacto con el mundo implacable de la materia; es una adherencia de la que no escapamos y que ninguna metáfora nos haría confundirlo con un objeto exterior. (...) Este sentimiento de identidad entre el yo y el cuerpo no permitirá pues jamás a aquéllos que quieran partir de él encontrar en el fondo de esa unidad, la dualidad de un espíritu libre que se debate contra el cuerpo al que habría sido engarzado. Para ellos al contrario, toda la esencia del espíritu consiste en ese encadenamiento.

Este es el término clave: "encadenamiento". El hitlerismo coloca en la base de su concepción del hombre el sentimiento del cuerpo, pero para convertirlo ahora en el centro de la vida espiritual. 
Lo biológico, con todo lo que comporta de fatalidad, se vuelve algo más que un objeto de la vida espiritual, se vuelve el corazón. Las misteriosas voces de la sangre, los llamados de la herencia y del pasado a los que el cuerpo sirve de enigmático vehículo, terminan perdiendo su naturaleza de problemas sometidos a la solución de un yo soberanamente libre. (...) La esencia del hombre no está en la libertad sino en una especie de encadenamiento. "Sangre y suelo" es la consigna del mayor ideólogo del nazismo, Alfred Rosenberg. Si la sociedad moderna se fundaba sobre el acuerdo de voluntades libres, éstas mismas serán vistas por el hitlerismo como frágiles e inconsistentes, falsas y mentirosas. La sociedad será de base consaguínea o no será. "Y si la raza no existe, ¡habrá que inventarla!"

¿Qué queda del espíritu universalista de la sociedad moderna? Nada, pues se asiste a su desmantelamiento: la universalidad se transforma en expansión, que por supuesto, requerirá de la fuerza bru- ta y que dejará un mundo de amos y esclavos. Pero aún hay algo más en el análisis de Levinas. ¿Qué diferencia veía entre el judaísmo y el hitlerismo? Justamente el paganismo de éste.

El paganismo no es nunca la negación del espíritu ni la ignorancia de un Dios único. El paganismo es una impotencia radical para salir del mundo. No consiste ni en negar el espíritu ni negar a Dios, sino en situarlos en el mundo. En este mundo autosuficiente, clausurado en sí mismo, el pagano está enfermo. Lo encuentra sólido y bien asentado. Lo encuentra eterno. Le dirige sus acciones y su sentido. El sentimiento de Israel en cuanto al mundo atañe, es completamente diferente. Lo encuentra sospechoso. El judío no encuentra en él los asideros definitivos del pagano.

Si transcendencia y liberación son valores de la civilización occidental, no es de extrañar que Levinas vea el fin de ésta en una filosofía que apuesta por el biologismo, por la necesidad, por la pesantez. Si el espíritu del hombre lo da la pertenencia a la sangre y a la tierra, ipor qué no organizar a los hombres según estos parámetros? De aquí podemos deducir tanto el racismo $^{10}$ como el nacionalismo ${ }^{11}$ del que hizo gala el nazismo. Pero cuidado, que esto no es un arcaísmo, es justo un momento más de la modernidad; el hitlerismo tenía a la "ciencia", estaba de su lado. 
W alter Benjamin es uno de los pensadores más idiosincrásicos, originales, antisistemáticos y crípticos de la historia del pensamiento. Su obra, cada vez más conocida, está recibiendo el reconocimiento debido -él nunca quiso ningún honor ni celebridad- porque pocos han pensado la crisis de la civilización como él. Tardó mucho en abandonar Francia porque quiso ver de cerca al "monstruo". El 25 de septiembre de 1940, cuando iba a cruzar la frontera franco-española por Port Bou, la policía franquista detiene al grupo con el que viajaba; sabiendo que sería entregado a la Gestapo se suicida esa misma noche ingiriendo tabletas de morfina. Tenía 48 años.

No hay un solo pensamiento de Benjamin que olvide a las víctimas del pasado o del presente para buscar su redención y esto se puede ver con claridad espigando sus ya famosas tesis en las que en el fondo se nos pide una lectura de la historia" a contrapelo". En cualquiera de ellas puede encontrar el lector un análisis tan lúcido como enigmático de la esencia de la barbarie. Leamos su octava tesis:

La tradición de los oprimidos nos enseña que el "estado de excepción" en el que vivimos es la regla. Debemos llegar a un concepto de historia que se corresponda con esta situación. Nuestra tarea histórica consistirá entonces en suscitar la venida del verdadero estado de excepción, mejorando así nuestra posición en la lucha contra el fascismo. El que sus adversarios se enfrenten a él en nombre del progreso, tomado éste por ley histórica, no es precisamente la menor de las fortunas del fascismo. No tiene nada de filosófico asombrarse de que las cosas que estamos viviendo sean "todavía" posibles en el siglo XX. Es un asombro que no nace de un conocimiento, conocimiento que de serlo tendría que ser éste: la idea de historia que provoca ese asombro no se sostiene.

"Estado de excepción", "regla", "verdadero estado de excepción"... la tesis es muy densa, porque en ella se resume una parte importantísima del pensamiento benjaminiano. Analizaremos el contenido con la ayuda de Reyes Mate ${ }^{12}$ y Michael Löwy ${ }^{13}$, dos grandes conocedores del pensamiento de Benjamin.
La perspectiva que adopta Benjamin es la de los vencidos, de ahí que "el estado de excepción sea la regla". ¿Era posible que cualquier integrante de este grupo se sorprendiera ante lo que estaba ocurriendo? ¿No es ésta la tónica de la historia? Lo único novedoso era que ese estado de excepción que siempre 
había existido para las víctimas llegara a un número mayor de personas, nada más. Pasemos ahora al concepto "estado de excepción" tan querido por Benjamin.

Este concepto va ligado a la persona de Carl Schmitt ${ }^{14}$ y al decisionismo. El estado de excepción es "la suspensión de todo orden existente". "En esa capacidad de suspender el derecho se manifiesta lo que caracteriza al soberano: crear derecho, convertir su decisión en ley". Pero esta suspensión del derecho no significa ni mucho menos que el suspendido quede libre de toda norma o desligado del derecho. Al contrario, queda a merced del poder pero sin la mediación de la norma; sigue vigente la fuerza de la ley sin la formalidad de la ley, y así el derecho queda dependiendo de la pura decisión del soberano.

Hitler, que llegó al poder por medios democráticos, suspendió todos los artículos de la democrática Constitución de Weimar mediante un decreto que nunca fue revocado. Alemania, pues, vivió bajo un estado de excepción que duró doce años.

Como bien apunta Reyes Mate, el interés benjaminiano por el estado de excepción es la superación del problema de la violencia. Para Benjamin, la violencia cumple dos funciones crea y mantiene el derecho, y dado que éste contamina la política, la pregunta es: ¿es posible una visión no violenta de la política? Sólo si se suspende el derecho, allá donde no hay norma sigue la vida su decurso natural. De ahí que este concepto fuese tan querido por Benjamin.

Pero no piensa así Schmitt. Para Schmitt, obsesionado por el caos, el estado de excepción era la panacea porque reforzaba la autoridad del poder al ubicar su legitimación en la pura decisión del soberano. El misterio del poder es, pues, la decisión. Había que hilar fino para que la suspensión del derecho no acabara en carnaval, es decir, en la liberación de toda norma. A eso se aplica Schmitt explicando la suspensión del derecho como sometimiento inmediato a la decisión del soberano sin mediación de ley alguna. Schmitt encamina la suspensión del derecho en una dirección que es la opuesta a la que apuntaba Benja$\min$.

De todo esto sólo cabe concluir que la excepcionalidad schmittiana mantiene la violencia política de una forma más extrema que el derecho, puesto que el súbdito queda abandonado a la voluntad del soberano. Pero esta violencia afecta de forma desigual a unos y otros.

"Los que están con el soberano están implicados en el gobierno mediante normas, es decir experimentan la decisión mitigada por la norma; el oprimido, sin embargo, está a merced del poder de decisión sin mediación posible. Para que el estado 
de excepción funcione, es decir, para poder dejar a parte de la sociedad en un espacio sin ley, es necesaria la presencia de la ley. Si todo fuera excepcionalidad estaríamos en el caos. Y aquí no se trata de un caos, sino de un sistema legal que puede ser para los oprimidos un estado permanente de excepción. (...) La respuesta de Benjamin a esa deconstrucción del derecho es declarar "el verdadero estado de excepción"."

Para romper esta lógica política que marginaba a una parte importante de la sociedad al sustentarse en la violencia "mítica" —la que crea y sostiene derecho- había que responder con una violencia "divina" -la que quiere acabar con todo tipo de violencia.

"Pero es violencia porque uno se la tiene que hacer a sí mismo: si la primera (mítica) exige sacrificios de los demás, la segunda (divina) se hace cargo de ellos. La violencia divina está dispuesta a defender la vida y morir por ella, porque ve en la vida física no sólo cuerpo sino la posibilidad de la justicia. La decisión, más allá de todo derecho, de hacerse cargo del sufrimiento o de la injusticia del otro, es el gesto gracias al cual una decisión excepcional pone fin al decisionismo del estado de excepción."

La pregunta puede parecer extraña, pero, ¿está Benjamin denunciando el estado de excepción en el hitlerismo? Básicamente no, porque quien ha declarado silenciosamente el estado de excepción es el derecho y, por tanto el Estado de Derecho, al que alude bajo la figura de "progreso". Si el único problema fuera el hitlerismo no sería difícil resolverlo, pero el asunto es mucho más grave. Hasta los que están contra el hitlerismo lo han hecho posible, porque se han asombrado de lo que ocurre, pero se han asombrado mal: hay que saber asombrarse.

Es propio de quienes no entienden cómo en una sociedad tan moderna puede florecer un producto tan anacrónico como el fascismo. Ese asombro no lleva a ninguna parte porque nace de un prejuicio que se toma por una verdad asentada: que el fascismo es un producto antiguo. El asombro productivo debería consistir en asombrarse de no ver la complicidad entre progreso y barbarie, entre Modernidad y fascismo.

Lo que realmente ha ocurrido, según Benjamin, es que ha faltado ese historiador que, gracias a un gesto fundamental, haya sabido asombrarse; por el contrario, son historiadores de corte historicista 
- "Ios que narran lo que realmente ocurrió" - los que se han adueñado del saber histórico. Este segundo tipo de historiadores y no el primero era el causante de que muchos ciudadanos, entre ellos Levy, no vieran la cruel racionalidad en los hechos.
Volvamos al final de la tesis, ya para concluir: "No tiene nada de filosófico asombrarse de que las cosas que estamos viviendo sean "todavía" posibles en pleno siglo XX. Es un asombro que no nace de un conocimiento, conocimiento que de serlo tendría que ser éste: la idea de historia que provoca ese asombro no se sostiene."

\title{
5. Una revolución espiritual recorre el mundo
}

\begin{abstract}
"Comienza hoy una de aquellas épocas en las cuales la Historia Universal debe ser escrita de nuevo. () Un sentimiento vital joven y que sin embargo se reconoce a sí mismo como antiquísimo, urge su plasmación."
\end{abstract}

\section{A} sí comienza El mito del siglo $X X$, obra del ideólogo Alfred Rosenberg ${ }^{15}$ y que durante unos años se convirtió en la Biblia del nazismo. Quizá el título engañe pues no se va a contar una historia que sucedió más allá de los tiempos y que se trae a colación para encontrar en ella una orientación vital, no, simplemente trata acerca de cómo se crea un nuevo Sujeto, alemán en este caso, protagonista fundamental de los nuevos tiempos que se avecinan. A pesar de sus muchas páginas no se espere encontrar ni razones ni argumentos; no se trata de pensar sino de "emocionar". Sin embargo, haremos un seguimiento de este texto acompañándonos de dos autores, excelentes conocedores del fenómeno nazi, Philippe Lacoue-Labarthe y Jean Luc Nancy ${ }^{16}$.
Dos son los puntos de partida para adentrarnos en esta obra:

1. Dado que el problema alemán es fundamentalmente un problema de identidad, la figura alemana del totalitarismo es el racismo.

2. Dado que el mito puede definirse como un aparato de identificación, la ideología racista se ha confundido con la construcción de un mito.

1.- Para comprender lo que los autores nos dicen, debemos recordar que el Estado alemán es un Estado tardío -1874- y que han pasado para entonces casi dos siglos viviendo de una cultura importada desde Francia o Italia. La Primera Guerra Mundial y las sanciones postbélicas, insultantes para Alemania, activaron ese proceso de iden- 
tificación del que aquí se nos habla. En palabras de nuestros autores, "lo que le ha faltado a Alemania es ser Sujeto de su propia historia" y esto se traduce en una enfermedad que no sería otra que la esquizofrenia. ¿Por qué? Veámoslo.

Un proceso de construcción de la identidad no se levanta en el vacío, debemos encontrar algún modelo ejemplar y ¿dónde encontrarlo? En la Antigua Grecia. Pero ocurre que este modelo ya ha servido a otros, así que tomarlo sería tomar la identidad de otro y no la propia. Es entonces cuando aparece la salida: no se identificará con esa Grecia de la mesura y de la claridad, sino con esa otra arcaica de los sacrificios sangrientos, de la ebriedad, del exceso. $Y$ de aquí tres consecuencias:

1. Promover un modelo histórico nuevo e inédito.

2. La Grecia arcaica proveía más energía identificatoria.

3. Estética podríamos Ilamar a esta última consecuencia porque Alemania reprodujo principalmente en la ópera - el drama total wagneriano- el festival trágico de los griegos.

Abundando un poco más en el comportamiento psicótico de la Alemania nazi, y puesto que el siguiente paso que vamos a dar será entrar en el proceso de construcción del mito, parece oportuno mencionar un texto del psiquiatra español Carlos Castilla del Pino, ya que puede arrojar más luz al asunto que tratamos. El delirio. Un error necesario ${ }^{17}$, así titula este ensayista una de sus obras más premiadas. La tesis central que se defiende en ella es que en el delirio no se cae, sino que se entra.

No vamos a utilizar el concepto de "normal" porque es estadístico y no psicológico, pero todos tenemos que movernos en una realidad determinada y según cómo lo hagamos se despertarán o no procesos psicopatológicos. En ocasiones, la realidad puede sernos tan hostil que nos resulte imposible vivirla, nos rebasa y a la vez nos ahoga. Este es el momento en el que el paciente -ipor qué no todo un pueblo? - se "crea una nueva realidad" en la que poder ubicarse y orientarse. Como se ve por lo hasta ahora dicho, la situación del pueblo alemán era insoportable y era más que necesario encontrar una salida, es decir, fabricar, construir un mito potente en el cual habitar, y eso es justo lo que intentaremos exponer a continuación.

2. El mito del siglo XX, de Alfred Rosenberg no es un texto de argumentaciones sino de afirmaciones. Estas se suceden, se acumulan dando la engañosa apariencia de verdad, pero nada más lejos de la realidad. Se pone de manifiesto la situación crítica a la que nos ha conducido la modernidad — de ahí esas frases rimbombantes con las que se inicia la obra- y la alternativa es el nazismo. Pero entremos en materia. 
El mito es así la potencia de unificación de las fuerzas y de las direcciones fundamentales de un individuo o de un pueblo, la potencia de una identidad subterránea, invisible, no empírica. Lo cual debe entenderse antes que nada por oposición a la identidad general, desencarnada, de lo que Rosenberg llama "absolutos sin límites", y que son todos los Dioses o todos Sujetos de la filosofía, el de Descartes o el de Rousseau o el de Marx. Contra esas identidades disueltas en la abstracción, el mito designa la identidad como diferencia propia, y su afirmación.

Otro aspecto de este mito es que es soñado, y Alemania no ha soñado aún su sueño - conviene recordar que la constitución del Estado alemán dejó fuera territorios que los alemanes consideraban como propios, lo que significa que la Gran Alemania era todavía una aspiración, y aquí comienza el sueño. Pero éste deberá poseer una forma determinada, tendrá pues que encarnarse en un tipo. Veamos la secuencia de construcción.

La libertad del alma es Gestalt (forma). Esta forma es plásticamente limitada - recuérdese la oposición al "absoluto sin límites". Esta forma está condicionada por la raza. Y esta raza es la figura exterior de un alma determinada ${ }^{18}$. Así, siguiendo a nuestros autores, "una raza es antes que nada el principio y el lugar de una potencia mítica". Una vez llegados aquí, podemos intuir el contenido del discurso que pronunció Rosenberg el 22 de febrero de 1934 ante todos los cargos políticos más importantes en esa fecha: "La lucha por la concepción del mundo": "TODA VISIÓN DEL MUNDO ES EXACTAMENTE TAN FUERTE COMO LA VOLUNTAD DE SUS PORTADORES EN DEFENDERLA. ESTA
ES LA ÚNICA VARA DE MEDIR PARA EL JUICIO SOBRE LAS LUCHAS HISTÓRICO-MUNDIALES" (en mayúsculas en el original). $Y$ de esto deriva cuando menos una consecuencia inmediata y plantea una pregunta acerca del pueblo judío.

Frente al cristianismo o al humanismo, que creen en la igualdad de todos los seres humanos, el nazismo los jerarquizará instituyendo así la desigualdad radical en función de ciertas características biológicas. Si todos los animales se aparean dentro de su especie, los hombres lo harán en el interior de su raza; cualquier mezcla sería el comienzo de la degeneración.

¿Sería el judío miembro de alguna raza? En absoluto. El judío no es que represente una raza mala o deforme, el judío es informe y al no tener forma no es nada, y esto lo deja claro Rosenberg cuando afirma contundentemente que "el judío no es el antípoda del germano, sino su contradicción". El judío lo más que puede hacer es contaminar y poner en peligro el resto de las razas, de ahí que deba ser tratado como un virus a exterminar.

Demos un paso más en este proceso. Ahora debemos hablar de la 
especificidad de una raza y un tipo, y ello exige dos determinaciones más:

1. La raza y el pueblo dependen de la sangre. Así el lema será "Sangre y suelo". La sangre es naturaleza, es selección natural —la supervivencia de los más aptos-, voluntad de diferencia - de nuevo en contra del absoluto sin límitesvoluntad de distinción.

2. Y, además, la raza será la aria ("ario" significa guerrero) porque es portadora del mito solar, puesto que para los nórdicos el espectáculo solar es impresionante por su rareza. Más todavía, la raza aria es el Sujeto.

El combate a partir de ahora, y volvemos al discurso de Rosenberg, será de cosmovisiones y al final sólo

\section{Notas}

$1 \quad$ Así se les llamó a los que previeron la catástrofe que se avecinaba.

2 Primo Levy, Si esto es un hombre, pg. 208

3 Walter Benjamin, VI Tesis, "Sobre el concepto de historia”, Taurus

4 M. Löwy, Aviso de incendio, pg. 76, FCE

5 J. M. Romero, Hacia una bermenéutica dialéctica, pgs 93-94, Síntesis

6 J.A.Zamora, T.W.Adorno: pensar contra la barbarie, pg. 28, Trotta. habrá una vencedora que se realizará en el nacional-socialismo.

Todo esto quedaría incompleto si no mencionáramos el impacto que una obra del historiador romano Publio Cornelio Tácito ejerció en esa época: Germania ${ }^{19}$. En dicha obra, considerada por algunos estudiosos como el primer tratado de antropología, Tácito llega a la conclusión de este pueblo ha debido mantenerse puro por la dificultad de acceso y por la ferocidad de sus habitantes. $Y$ esto no pasó inadvertido a los ideólogos a la hora de construir el mito. Construido ya el mito, éste deberá tomar cuerpo en distintas instituciones que lo alimentarán. Pues bien, una de ellas es el Estado totalitario. A él van dedicadas la próxima parte de este trabajo.

7 A. Neher, El exilio de la palabra. Del silencio bíblico al silencio de Auschwitz, pgs. 143-145, Riopiedras

8 E. Levinas, Unas reflexiones acerca de la filosofía del hitlerismo, FCE

9 Conviene recordar que dentro de la jerarquía racial, el judío no pertenece a ninguna raza, porque no la tiene, es la anti-raza, es quien corrompe las razas. El pico y las garras de águila, uno de los símbolos básicos del nazismo, tenía varios significados: el pico y las garras representaban las armas de las que dispone el Estado para defenderse y también espiritualidad. La serpiente que portan las garras es el Mal, el pueblo judío. 
Sobre si Hitler trnía conciencia de estar haciendo el mal, Efraim Zuroff, director del Centro Simon Wiesenthal, exclamó: "Por supuesto que no! iHitler se creía un médico! ¡Mataba gérmenes! iEso eran los judíos para él!”. El caso de Himmler era similar: "Por lo que respecta al antisemitismo, es exactamente lo mismo que el despiojamiento. No hay cosmovisión alguna involucrada en quitarse los piojos, es tan sólo cuestión de higiene. Pronto estaremos despiojados." (Rosa Sala, Mitos y simbolos del nazismo, El acantilado)

Quizá no esté de más precisar algo más el término racismo. "La palabra "racismo", en su acepción común, designa dos dominios muy distintos de la realidad: se trata por un lado de un comportamiento, que la mayoría de las veces está constituido por odio y menosprecio con respecto a personas que poseen características físicas bien definidas y distintas a las nuestras; y por el otro, de una ideología concerniente a las razas humanas. No necesariamente se encuentran los dos presentes al mismo tiempo. El racista ordinario no es un teórico, no es capaz de justificar su comportamiento mediante argumentos "científicos"; y viceversa, el ideólogo de las razas no es necesariamente un racista, en el sentido que comúnmente tiene esta palabra, y sus puntos de vista teóricos pueden no ejercer la más mínima influencia sobre sus actos; o bien es posible que su teoría no implique que haya razas intrínsecamente malas. Con el objeto de separar estos dos sentidos, se adoptará aquí la distinción que a veces se hace entre racismo, término que designa el comportamiento, y racialismo, que se reserva a las doctrinas. Es preciso agregar que el racismo que se apoya en un racialismo, produce resultados realmente catastróficos: éste se el caso del nazismo.” (T. Todorov, Nosotros y los otros, Siglo XXI)

11 El nacionalismo fue el arma que utilizaron para acabar con la lucha de clases, pues siendo todos alemanes, formaban parte de un mismo engranaje, de una misma maquina, y por ello todas las "piezas" eran necesarias cada una cumpliendo la función prescrita.

12 Reyes Mate, Medianoche en la historia, Trotta

13 Michael Löwy, Aviso de incendio, FCE

14 Un excelente estudio de la obra de este jurista puede encontrarse en Germán Gómez Orfanel, Excepción y normalidad en la obra de C. Schmitt, CEC.

15 Alfred Rosenberg, El mito del siglo $X X$ ” Biblioteca Nacionalsocialista

Iberoamericana

16 P. Lacoue-Labarthe, J. L. Nancy, El mito nazi, Anthropos

17 C. Castilla del Pino, El delirio, un error necesario, Nobel

18 Recuérdese lo escrito por Lévinas.

19 P. C. Tácito, Germania, Gredos. 